\title{
ESTABILIDADES QUÍMICA, FÍSICO-QUÍMICA E MICROBIOLÓGICA DE SUCO DE LARANJ A CV. "PERA" SUBMETIDO A DIFERENTES CONDIÇÕES DE ESTOCAGEM
}

\author{
PATRICIA TEIXEIRA DA SILVA* \\ ELIANE FIALHO** \\ MARCO ANTÔNIO LEMOS MIGUEL*** \\ MARIA LÚCIA MENDES LOPES****

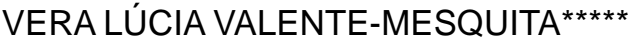

\begin{abstract}
Este estudo teve como objetivo avaliar as estabilidades química, físico-química e microbiológica de suco de laranja cv. "Pêra", mantido em temperatura ambiente, estocado sob refrigeração ou sob congelamento durante diferentes períodos. Determinaram-se os teores de ácido ascórbico e de sólidos solúveis totais, a acidez total titulável e o pH dos sucos. Foram realizadas, também, as contagens de bactérias heterotróficas aeróbias mesófilas, fungos miceliais e leveduras, bactérias láticas, coliformes totais e fecais e Salmonella. Os teores de ácido ascórbico e de sólidos solúveis totais dos sucos permaneceram estáveis durante o período de estocagem nas condições estudadas. O mesmo foi observado para acidez total titulável e $\mathrm{pH}$, exceto para os sucos congelados em que houve alteração desses parâmetros a partir de 120 dias de estocagem. Não foram encontrados Salmonella spp. e Coliformes totais e fecais nas amostras estudadas. A contagem inicial de bactérias heterotróficas aeróbias mesófilas, fungos miceliais e leveduras e bactérias láticas foi de aproximadamente 3 Log UFC/mL. No suco mantido em temperatura ambiente durante 24 horas observou-se aumento de 1,5, 2,3 e 3,4 Log UFC/ $\mathrm{mL}$ na contagem de bactérias heterotróficas aeróbias mesófilas, fungos miceliais e leveduras e bactérias láticas, respectivamente. Nos sucos refrigerados, a contagem microbiana não excedeu a inicial até o quarto dia. Nos sucos congelados, a carga microbiana permaneceu inferior à inicial durante 180 dias de estocagem. De acordo com os resultados obtidos, o suco de laranja in natura preserva sua qualidade quando estocado sob refrigeração durante 48 horas ou sob congelamento durante 120 dias.
\end{abstract}

PALAVRAS-CHAVE: ESTABILIDADE QUÍMICA; ESTABILIDADE MICROBIOLÓGICA; SUCO DE LARANJA.

* Mestranda do Programa de Pós-Graduação em Nutrição, Instituto de Nutrição Josué de Castro, Universidade Federal do Rio de Janeiro (UFRJ), Rio de Janeiro (e-mail: kakissa2002@yahoo.com.br).

** Doutora em Ciências, Professora Adjunta, Instituto de Nutrição Josué de Castro, UFRJ, RJ (e-mail:elianefialho@yahoo.com.br).

*** Doutor em Ciências, Professor Adjunto, Instituto de Microbiologia Prof. Paulo de Góes, UFRJ, RJ (e-mail: marco.miguel@micro.ufrj.br).

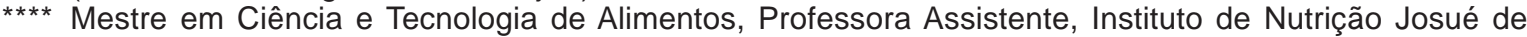
Castro, UFRJ, RJ (e-mail: mlucia@nutricao@ufrj.br).

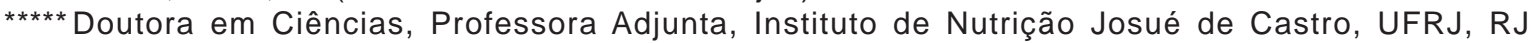
(e-mail:valentem@nutricao.ufrj.br). 


\section{INTRODUÇÃO}

É crescente a busca dos consumidores por alimentos de qualidade, que sejam saudáveis e com pouca ou nenhuma adição de conservantes (BULL et al., 2004). No entanto, a perda de nutrientes durante a estocagem pode representar fator limitante para o consumo de produtos in natura, principalmente os sucos de frutas (ÖZKAN, AYSEGÜL e CEMEROGLU, 2004; KABASAKALIS, SIOPIDOU E MOSHATOU, 2000).

A vitamina C é usada como índice de qualidade nutricional de produtos derivados de frutas por ser mais sensível à degradação durante o processamento e subseqüente estocagem em relação a outros nutrientes (ÖZKAN, AYSEGÜL e CEMEROGLU, 2004). O ácido L-ascórbico (AA), uma das formas ativas da vitamina $C$, é susceptível à degradação por calor, luz, oxidação e íons metálicos (DEUTSCH, 2000).

Devido à importância nutricional que representa e ao fato de não ser sintetizada pelo organismo humano, a ingestão da vitamina $C$ na alimentação diária torna-se indispensável para garantir a manutenção das funções biológicas (SILVA, 2005). Atribui-se o efeito protetor da vitamina $C$ no organismo às propriedades antioxidantes, que diminuem o risco de doenças crônicas nãotransmissíveis (BINGHAM e RIBOLI, 2004; NAIDU, 2003; ARRIGONI e TULLIO, 2002; KAUR e KAPOOR, 2001). Essa vitamina atua, na prevenção e cura de escorbuto e anemia ferropriva, além de evitar a formação de nitrosaminas no intestino (NAIDU, 2003; ARRIGONI e TULLIO, 2002; ALMEIDA et al., 2003).

O suco de laranja, alimento rico em nutrientes, é reconhecido como importante fonte de vitamina C (FALVELA, 2004; ALMEIDA et al., 2002; ECONOMOS e CLAY, 1999). O consumo desse suco, difundido em diversas partes do mundo, deve-se ao aroma e sabor agradáveis e ao custo relativamente baixo (ÖZKAN, AYSEGÜL e CEMEROGLU, 2004; SELLI, CABAROGLU e CANBAS, 2004; LEE e COATES, 1999). O Brasil é o maior produtor mundial de frutas cítricas (FAO, 2004), com destaque para a produção de laranja da cv. "Pêra" (OLIVEIRA et al., 2002). A comercialização do suco de laranja assumiu fundamental importância para a economia brasileira e gera divisas que ultrapassam um bilhão de dólares por ano (NEVES et al., 2001).

A qualidade da fruta constitui o principal fator que pode interferir na aceitação do suco de laranja. Os teores de AA e de sólidos solúveis totais, bem como a contagem de microrganismos, são usados como parâmetros para avaliar a qualidade do suco de laranja (OLIVEIRA et al., 2002). A alta acidez das frutas cítricas inibe o desenvolvimento de microrganismos patogênicos (CORRÊANETO e FARIA, 1999), mas permite o desenvolvimento de bactérias láticas e de fungos miceliais e leveduras que podem gerar sabor e odor desagradáveis (POLYDERA, STOFOROS e TAOUKIS, 2003). De acordo com PARISH (1991), pH em torno de 3,4 a 4,0, baixas temperaturas de estocagem e condições adequadas de higienização podem aumentar o período de conservação dos sucos.

Há estudos que avaliam o efeito do processamento sobre a estabilidade da vitamina $\mathrm{C}$ em sucos de frutas in natura (BULL et al., 2004; BURDURLU, KOCA e KARADENIZ, 2006; ESTEVE et al., 2005; SILVA et al., 2005; JOHNSTON e BOWLING, 2002; AYHAN et al., 2001). No entanto, estudos que descrevam a estabilidade dessa vitamina e da microbiota natural do suco de laranja in natura em função do tempo e da temperatura de estocagem não foram encontrados.

O objetivo do presente estudo foi avaliar as estabilidades química, físico-química e microbiológica do suco in natura de laranja cv. "Pêra", submetido a diferentes condições de tempo e temperatura de estocagem.

\section{MATERIAL E MÉTODOS}

\subsection{PREPARO DAS AMOSTRAS}

Amostras de laranja, cv. "Pêra", foram adquiridas em mercado varejista da cidade do Rio de Janeiro. As frutas foram selecionadas, lavadas em água fria e corrente, imersas por 15 minutos em solução contendo $1 \mathrm{~mL}$ de detergente neutro por $100 \mathrm{~mL}$ de água, enxaguadas e imersas em solução com $100 \mathrm{~g} / \mathrm{L}$ de hipoclorito de sódio por 10 minutos. O suco foi extraído em centrífuga 
comercial (Comil, Brasil), subdividido em alíquotas de $200 \mathrm{~mL}$, sendo uma alíquota analisada imediatamente após a extração do suco. As demais foram acondicionadas em embalagens de polietileno hermeticamente fechadas e estocadas em temperatura ambiente $\left(23^{\circ} \mathrm{C}\right)$ durante 24 horas; sob refrigeração $\left(4^{\circ} \mathrm{C}\right)$ por sete dias, e sob congelamento $\left(-23^{\circ} \mathrm{C}\right)$ durante 180 dias. Todas as alíquotas foram submetidas às análises químicas, físico-químicas e microbiológicas.

\subsection{ANÁLISES QUÍMICAS}

O teor de AA foi determinado por cromatografia a líquido de alta eficiência (CLAE) conforme metodologia descrita por PAULO et al. (1999). Utilizou-se cromatógrafo a líquido de alta eficiência Shimadzu (Kyoto, Japão), adaptado com bomba LC-10AD, controlado com software de dados Class LC-10 (Shimadzu) e detector ultra-violeta (UV) de fotodiodo SPD-M10A.

As condições analíticas empregadas foram: fase móvel constituída de solução tampão de fosfato de potássio com concentração de $2 \mathrm{mg} / 100 \mathrm{~g}\left(\mathrm{KH}_{2} \mathrm{PO}_{4}\right)$ e pH 2,3 ajustado com ácido clorídrico 36,5 g/L, coluna C-18, fluxo de $0,4 \mathrm{~mL} / \mathrm{min}$, volume injetado de amostra de $200 \mu \mathrm{L}$ e comprimento de onda a $243 \mathrm{~nm}$.

Efetuou-se a quantificação do ácido ascórbico segundo o método de padrão externo. A solução padrão de ácido ascórbico foi preparada com 10,9 mg de AA, diluído em $1900 \mu \mathrm{L}$ de tampão $\mathrm{KH}_{2} \mathrm{PO}_{4}$ e adicionado de $100 \mu \mathrm{L}$ de ditiotreitol $(5 \mathrm{mg} / \mathrm{mL})$. Volumes de $5 \mu \mathrm{L}, 10 \mu \mathrm{L}, 15 \mu \mathrm{L}$, $20 \mu \mathrm{L}, 25 \mu \mathrm{L}, 30 \mu \mathrm{L}$ e $40 \mu \mathrm{L}$ dessa solução, que correspondem a 2,7 $\mu \mathrm{g}, 5,5 \mu \mathrm{g}, 8,2 \mu \mathrm{g}, 10,9 \mu \mathrm{g}$, $13,6 \mu \mathrm{g}, 16,4 \mu \mathrm{g}$ e $21,9 \mu \mathrm{g}$ de ácido ascórbico, foram diluídos em tampão $\mathrm{KH}_{2} \mathrm{PO}_{4}$ até completar o volume de $2 \mathrm{~mL}$. Alíquotas de $200 \mu \mathrm{L}$ dessas soluções foram submetidas às análises por CLAE, em duplicata, para quantificação do teor de AA e os resultados expressos em $\mu \mathrm{g}$ de AA/ mAbs.

Para a quantificação do teor de AA em suco de laranja, as amostras foram centrifugadas duas vezes a $10.000 \mathrm{~g}$ por 5 minutos. Alíquotas de $200 \mu \mathrm{L}$ do sobrenadante foram diluídas em $800 \mu \mathrm{L}$ de solução tampão de fosfato de potássio. Em seguida, $200 \mu \mathrm{L}$ dessa solução foram submetidos à análise por CLAE, nas mesmas condições relatadas anteriormente e os resultados expressos em $\mathrm{mg}$ de ácido ascórbico $/ 100 \mathrm{~mL}$ de suco de laranja.

A acidez total titulável (ATT) foi determinada em triplicata, de acordo com o método número 942.15A da AOAC (1995) e expressa em g de ácido cítrico anidro por $100 \mathrm{~mL}$ de amostra.

\subsection{ANÁLISES FÍSICO-QUÍMICAS}

O teor de sólidos solúveis totais (SST) foi determinado em refratômetro (Eppendorf 2763, Brasil), expresso em graus Brix, e o pH aferido em pHmetro (Incibras, Brasil). Essas análises foram realizadas em duplicata de acordo com a AOAC (1995), métodos número 983.17 e 942.15B, respectivamente.

\subsection{ANÁLISES MICROBIOLÓGICAS}

Para a quantificação microbiana, alíquotas de $10 \mathrm{~mL}$ de suco de laranja foram diluídas serialmente em água peptonada estéril $(0,1 \mathrm{~g} / 100 \mathrm{~mL})$. Bactérias heterotróficas aeróbias mesófilas, bactérias láticas e fungos miceliais e leveduras foram quantificados, respectivamente, em ágar padrão de contagem (APC) incubado a $37^{\circ} \mathrm{C}$ durante 48 horas; ágar Man, Rogosa e Sharpe (MRS) a $25^{\circ} \mathrm{C}$ por sete dias; e ágar batata dextrose (ABD), $\mathrm{pH} 3,5$ a $25^{\circ} \mathrm{C}$ por cinco dias. Essas determinações foram realizadas em duplicata.

Coliformes totais e fecais foram determinados pela técnica do Número Mais Provável em caldo verde brilhante a $2,0 \mathrm{~g} / 100 \mathrm{~mL}$, caldo Bile e caldo EC, respectivamente. Salmonella spp. foi determinada por pré-enriquecimento em caldo lactose, seguido de enriquecimento seletivo em caldo tetrationato e plaqueamento seletivo em ágar Mac Conkey e Hektoen.

Todas as análises microbiológicas foram realizadas de acordo com o Standard Methods for Microbiological Examination of Foods (BRACKETT e SPLITTSTOESSER, 1992) e os resultados expressos em unidade logarítmica (Log) de unidades formadoras de colônias (UFC) por mililitro. 


\subsection{ANÁLISES ESTATÍSTICAS}

Os dados obtidos foram submetidos à análise de variância ANOVA, seguido do teste de Tukey ou análise de regressão (LAPPONI, 2000). Determinou-se a significância estatística a 5\% de probabilidade, utilizando o software estatístico Excel 2000 (Microsoft Corporation).

\subsection{REAGENTES}

Todos os meios de cultura e reagentes utilizados foram adquiridos da empresa Merck com exceção do ditiotreitol, fornecido pela na empresa Sigma Aldrich Chemicals.

\section{RESULTADOS E DISCUSSÃO}

\subsection{ANÁLISES QUÍMICAS}

A Figura 1 apresenta a curva de calibração da solução padrão de ácido ascórbico obtida por CLAE e cromatograma típico da solução padrão de AA (inset). Os sucos de laranja armazenados em temperatura ambiente por 24 horas, sob refrigeração durante sete dias (Figura 2, inset) e sob congelamento durante 180 dias (Figura 3, inset) apresentaram tempo de retenção e perfis cromatográficos semelhantes aos da solução padrão.

Não foi observada diferença significativa entre o teor médio de AA do suco de laranja recémextraído ( $28 \mathrm{mg} / 100 \mathrm{~mL}$ ) e o do suco de laranja armazenado em temperatura ambiente por $24 \mathrm{~h}$ $(28,5 \mathrm{mg} / 100 \mathrm{~mL})$. Dados sobre a estabilidade do AA em suco de laranja armazenado em temperatura ambiente, publicados na literatura envolvem sucos submetidos a algum tipo de processamento. Não foram encontrados estudos que avaliem esse parâmetro em suco in natura. BURDURLU, KOKA e KARADENIZ et al. (2006) analisaram a degradação da vitamina $C$ em suco de laranja concentrado armazenado a $28^{\circ} \mathrm{C}$ e observaram retenção de $83,68 \%$ de AA após oito semanas. ZERDIN, ROONEY e VERMUË (2003) avaliaram o teor de AA em sucos de laranja industrializados, embalados em garrafas com barreira de oxigênio e observaram retenção de $80,21 \%$ após armazenamento a $25^{\circ} \mathrm{C}$ durante três dias.

\section{FIGURA 1 - CURVA DE CALIBRAÇÃO DA SOLUÇÃO PADRÃO DE ÁCIDO ASCÓRBICO - INSET APRESENTA CROMATOGRAMA DA SOLUÇÃO PADRÃO DE AA}

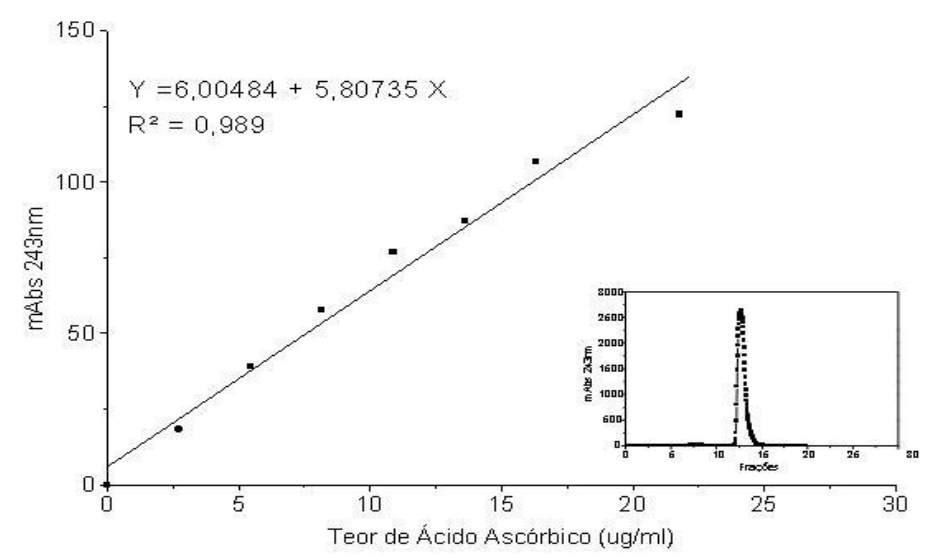

O teor médio de AA do suco de laranja refrigerado manteve-se estável durante sete dias (Figura 2). OLIVEIRA et al. (2002) observaram 99,5 \% de retenção de AA em suco de laranja cv. "Pêra", após armazenamento com etileno e estocado sob refrigeração durante 25 dias. No presente estudo, o período de estocagem sob refrigeração não foi superior a sete dias em razão das amostras não terem sido submetidas a nenhum tipo de processamento. 


\section{FIGURA 2 - TEOR MÉDIO DE ÁCIDO ASCÓRBICO EM SUCO DE LARANJA DA cv. "PÊRA", ESTOCADO SOB REFRIGERAÇÃO $\left(4^{\circ} \mathrm{C}\right)$ - INSET APRESENTA CROMATOGRAMA DE AMOSTRA DE SUCO DE LARANJA AOS 7 DIAS DE ESTOCAGEM}

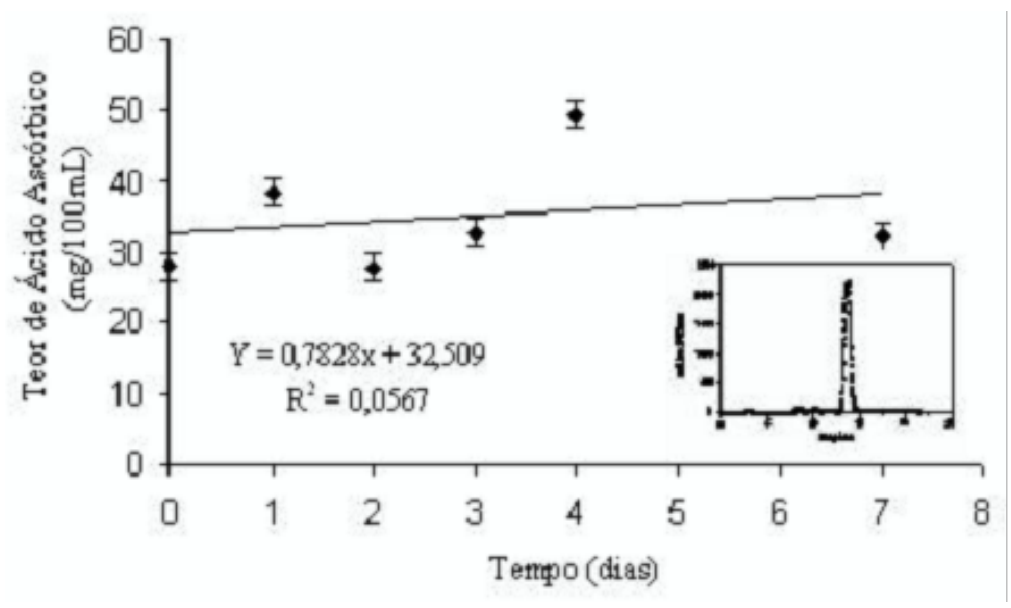

Durante os 180 dias de estocagem sob congelamento, o teor médio de AA no suco de laranja permaneceu estável (Figura 3). Não foram encontrados estudos sobre a estabilidade do AA em suco de laranja in natura armazenado sob congelamento. CAMPELO et al. (1998) analisaram a estabilidade do teor de AA em polpa congelada de acerola (Malpighia glabra L.) e observaram retenção de $62 \%$ dessa vitamina após 365 dias de estocagem. CORTE-ELEUTÉRIO e SALGADO (1997) constataram que o teor de AA permaneceu estável no suco de acerola, com $83,7 \%$ de retenção, quando estocado a $-18^{\circ} \mathrm{C}$ durante 270 dias. Acredita-se que a diferença observada nos percentuais de retenção de AA seja decorrente de peculiaridades na composição das diferentes frutas. De acordo com CORTE-ELEUTÉRIO e SALGADO (1997), a redução do teor de AA em sucos de frutas pode ser atribuída à oxidação que pode ter início no processo de extração do suco e continuar durante o período de estocagem. A estabilidade do AA observada no presente estudo pode ser devida à presença de compostos fenólicos, capazes de inibir a oxidação enzimática e não-enzimática do AA (ÖZKAN, AYSEGÜL e CEMEROGLU, 2004).

FIGURA 3 - TEOR MÉDIO DE ÁCIDO ASCÓRBICO EM SUCO DE LARANJA DA cV. "PÊRA", ESTOCADO SOB CONGELAMENTO $\left(-23^{\circ} \mathrm{C}\right)$ - INSET APRESENTA CROMATOGRAMA DE AMOSTRA DE SUCO DE LARANJA AOS 120 DIAS DE ESTOCAGEM

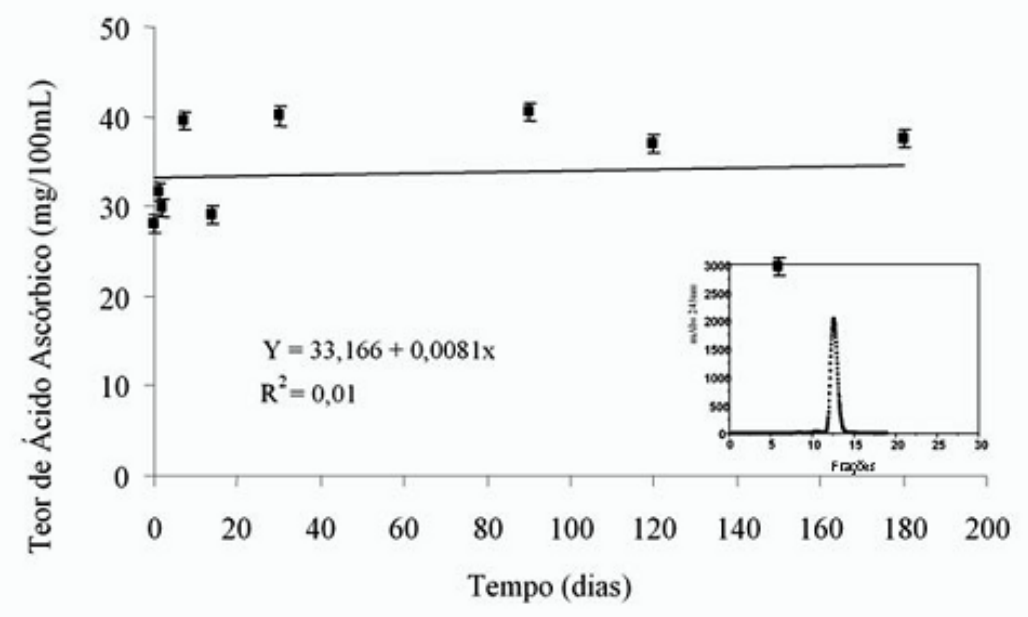




\subsection{PARÂMETROS QUÍMICOS E FÍSICO-QUÍMICOS}

A Tabela 1 apresenta os resultados dos parâmetros físico-químicos analisados no suco de laranja recém-extraído, armazenado em temperatura ambiente, sob refrigeração e sob congelamento. O teor de SST, parâmetro relacionado ao estágio de maturação da fruta, permaneceu estável independente das temperaturas e dos tempos de estocagem. Na amostra de suco de laranja armazenada em temperatura ambiente foi observado aumento de $0,2 \mathrm{~g} / 100 \mathrm{~g}$ de ácido cítrico anidro na ATT em relação ao suco recém-extraído, além de redução do pH. No suco de laranja armazenado sob refrigeração, a concentração de ATT variou de 1,1 a 1,3 g/100 g de ácido cítrico anidro e o pH variou entre 3,1 a 3,5 durante os sete dias de armazenamento. A ATT e o pH permaneceram estáveis no suco armazenado sob congelamento até 120 dias. No entanto, após esse período de estocagem observou-se redução da ATT com conseqüente aumento do pH. BULL et al. (2004) também verificaram aumento do $\mathrm{pH}$ e redução da acidez em suco de laranjas da cv. "Navel", colhidas em diferentes épocas do ano, uma vez que o pH do suco dessa cultivar aumenta durante a estação de colheita. Esses mesmos autores relatam que a época mais tardia da colheita das laranjas da cv. "Valencia" contribuíram para menor acidez e pH mais elevado no suco. ESTEVE et al. (2005) observaram valores de $\mathrm{pH}$ menores em amostras de suco de laranja que apresentaram maiores valores de acidez. Afirmaram, ainda, que as variações do $\mathrm{pH}$ durante a estocagem a $4^{\circ} \mathrm{C}$ e a $10^{\circ} \mathrm{C}$ mostram-se menos pronunciadas do que as variações da acidez. OLIVEIRA et al. (2002) encontraram valores de ATT ( $0,8 \mathrm{mg} / 100 \mathrm{~g}$ de ácido cítrico anidro) e de SST ( $8.8^{\circ} \mathrm{Brix}$ ) em suco recém-extraído de laranja, cv. "Pêra", menores do que os descritos no presente estudo.

\section{TABELA 1 - PARÂMETROS FÍSICO-QUÍMICOS DO SUCO DE LARANJA RECÉM-EXTRAÍDO (SLRE) DA cV. "PÊRA", ESTOCADO EM TEMPERATURA AMBIENTE $\left(23^{\circ} \mathrm{C} / \mathrm{SLTA}\right)$, SOB REFRIGERAÇÃO ( $\left.4^{\circ} \mathrm{C} / \mathrm{SLR}\right)$ E SOB CONGELAMENTO $\left(-23^{\circ} \mathrm{C} / \mathrm{SLC}\right)$}

\begin{tabular}{|c|c|c|c|c|c|c|c|c|c|c|c|c|}
\hline \multirow[t]{2}{*}{ Dias } & \multicolumn{3}{|c|}{ SLRE } & \multicolumn{3}{|c|}{ SLTA } & \multicolumn{3}{|c|}{ SLR } & \multicolumn{3}{|c|}{ SLC } \\
\hline & $\mathrm{pH}$ & SST & ATT & $\mathrm{pH}$ & SST & ATT & $\mathrm{pH}$ & SST & ATT & $\mathrm{pH}$ & SST & ATT \\
\hline 0 & 3,3 & 11 & 1,2 & & & & & & & & & \\
\hline 1 & & & & 3,1 & 10,5 & 1,4 & 3,2 & 11 & 1,1 & 3,3 & 11 & 1,1 \\
\hline 2 & & & & & & & 3,1 & 11 & 1,3 & 3,1 & 11 & 1,2 \\
\hline 3 & & & & & & & 3,2 & 11 & 1,2 & & & \\
\hline 4 & & & & & & & 3,5 & 10,5 & 1,3 & & & \\
\hline 7 & & & & & & & 3,3 & 11 & 1,3 & 3,3 & 10,5 & 1,2 \\
\hline 15 & & & & & & & & & & 3,0 & 10,5 & 1,2 \\
\hline 30 & & & & & & & & & & 3,3 & 11,5 & 1,3 \\
\hline 60 & & & & & & & & & & 3,5 & 10,5 & 1,4 \\
\hline 90 & & & & & & & & & & 3,3 & 11,5 & 1,2 \\
\hline 120 & & & & & & & & & & 3,4 & 10,5 & 1,2 \\
\hline 150 & & & & & & & & & & 3,6 & 12 & 0,9 \\
\hline 180 & & & & & & & & & & 4,0 & 11 & 0,6 \\
\hline
\end{tabular}

SST = sólidos solúveis totais; ATT = acidez total titulável.

Os resultados apresentados foram analisados em duplicata e o erro-padrão não foi significativo a 5\% de probabilidade.

Os processos de hidrólise, oxidação, ou fermentação modificam a concentração de íons hidrogênio e, conseqüentemente, a acidez dos alimentos (IAL, 1985). De acordo com VENDRAMINI e TRUGO (2000), o aumento do pH pode sugerir desequilíbrio na dissociação de ácidos em função do tempo de estocagem. Os ácidos orgânicos, que contribuem para o aroma e sabor do suco de laranja, podem ser resultantes de processos bioquímicos ou, em caso de fermentações, do desenvolvimento de microrganismos deteriorantes (ESTEVE et al. 2005).

\subsection{ANÁLISES MICROBIOLÓGICAS}

Não foi detectada a presença de Salmonella spp., bem como de coliformes totais e fecais em nenhuma das amostras analisadas. Esses resultados estão de acordo com o preconizado pela legislação 
brasileira, que estabelece o máximo de $10 \mathrm{NMP} / \mathrm{mL}$ de coliformes fecais e ausência de Salmonella spp. em $25 \mathrm{~mL}$ de amostra de suco de fruta (BRASIL, 2001). Embora o suco de laranja, devido à acidez, não constitua meio favorável à multiplicação de microrganismos patogênicos (POLYDERA, STOFOROS e TAOUKIS, 2003), casos de contaminação por Salmonella spp. em sucos de laranja não-pasteurizados foram reportados pelo AUSTRALIAN DEPARTMENT OF HEALTH AND AGEING (1999).

A legislação brasileira (BRASIL, 2001) não estabelece limites para a contagem de bactérias láticas e heterotróficas aeróbias mesófilas, bem como para fungos miceliais e leveduras em sucos de frutas. No entanto, as amostras de suco de laranja foram submetidas a essas análises a fim de verificar suas condições higiênico-sanitárias e o efeito das temperaturas de estocagem sobre a contagem microbiana. O suco de laranja recém-extraído apresentou contagem inicial de 3,14 Log UFC/mL para bactérias heterotróficas aeróbias mesófilas, 3,44 Log UFC/mL para fungos miceliais e leveduras e 3,35 Log UFC/mL para bactérias láticas (Figura 4). Estudos anteriores relataram contagens iniciais de fungos miceliais e leveduras de 2 Log UFC/mL (ALMEIDA, 2002) e 4 Log UFC/mL (MACHADO e RODRIGUES, 2002), superiores aos encontrados neste estudo. A reduzida contagem microbiana inicial observada pode ser atribuída à eficácia do processo de higienização a que as laranjas foram submetidas antes da extração do suco. O processo de higienização pode reduzir o número de microrganismos da parte externa da fruta, considerada a principal fonte de contaminação do suco (DOGAN e ERKMEN, 2004; LOPES et al. 2003).

O suco de laranja estocado em temperatura ambiente, quando comparado ao suco de laranja recém-extraído, apresentou aumento de 1,5, 2,3 e 3,4 Log UFC/mL, respectivamente, para bactérias heterotróficas aeróbias mesófilas, fungos miceliais e leveduras e bactérias láticas. Nos sucos de laranja armazenados sob refrigeração e sob congelamento foram observadas reduções de 2,1, 2,22 e 2,4 Log UFC/mL nas contagens de bactérias heterotróficas aeróbias mesófilas, fungos miceliais e leveduras e bactérias láticas, respectivamente (Figura 4). Esses resultados confirmam a eficiência das baixas temperaturas de estocagem na inibição do crescimento microbiano e indicam que apenas a acidez do suco não foi suficiente para prevenir a proliferação de microrganismos. KOPELMAN e RAUCHWERGER (1984), ao analisarem a cinética de crescimento microbiano em suco de laranja cv. "Shamouti", observaram elevação na contagem de fungos miceliais e leveduras proporcional ao aumento da temperatura de estocagem.

\section{FIGURA 4 - CONTAGEM DE BACTÉRIAS MESÓFILAS, FUNGOS FILAMENTOSOS E LEVEDURAS E BACTÉRIAS LÁTICAS EM SUCO DE LARANJA RECÉM-EXTRAÍDO (SLRE) DA cv. "PÊRA", ESTOCADO EM TEMPERATURA AMBIENTE (23ํㅣSLTA), SOB REFRIGERAÇÃO ( $\left.4^{\circ} \mathrm{C} / \mathrm{SLR}\right)$ E SOB CONGELAMENTO $\left(-23^{\circ} \mathrm{C} / \mathrm{SLC}\right)$ DURANTE 24 HORAS}

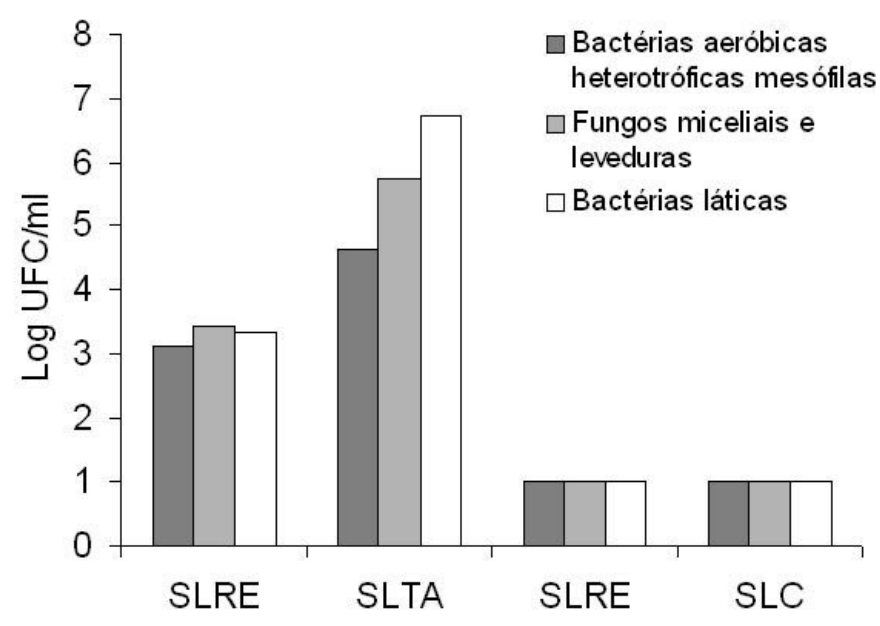


A Figura 5 apresenta os resultados da contagem microbiana do suco de laranja armazenado por sete dias sob refrigeração. Durante as primeiras 24 horas de estocagem observou-se redução de 2,14, 2,25 e 2,44 Log UFC/mL na contagem de bactérias heterotróficas aeróbias mesófilas, bactérias láticas e de fungos miceliais e leveduras, respectivamente. A partir de então, a contagem microbiana estabilizou ou apresentou aumento dependendo do tipo de microrganismo. Os resultados do presente estudo coincidem com os relatados por SADLER, PARISH e WICKER (1992).

\section{FIGURA 5 - CONTAGEM DE BACTÉRIAS MESÓFILAS, FUNGOS FILAMENTOSOS E LEVEDURAS E BACTÉRIAS LÁTICAS EM SUCO DE LARANJA cV. "PÊRA", ESTOCADO SOB REFRIGERAÇÃO ( $\left.4^{\circ} \mathrm{C} / \mathrm{SLR}\right)$ DURANTE 7 DIAS}

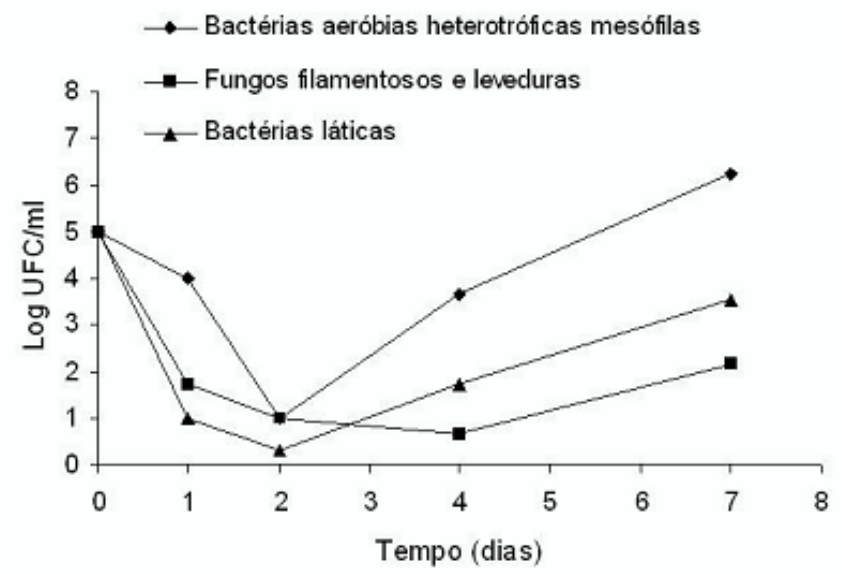

A Figura 6 mostra a contagem microbiana do suco de laranja armazenado sob congelamento durante 180 dias. A contagem de bactérias heterotróficas aeróbias mesófilas, fungos miceliais e leveduras e de bactérias láticas evidenciou redução de 2,66, 3,26 e 2,35 Log UFC/mL, respectivamente, até 48 horas. A contagem de bactérias láticas permaneceu estável em 1 Log UFC/mL a partir de 15 dias de estocagem. A contagem de bactérias heterotróficas aeróbias mesófilas e de fungos miceliais e leveduras ficou abaixo de 3 Log UFC/mL durante os 180 dias de estocagem.

\section{FIGURA 6 - CONTAGEM DE BACTÉRIAS MESÓFILAS, FUNGOS FILAMENTOSOS E LEVEDURAS E BACTÉRIAS LÁTICAS EM SUCO DE LARANJA cV. "PÊRA", ESTOCADO SOB CONGELAMENTO $\left(-23^{\circ} \mathrm{C} / \mathrm{SLC}\right)$ DURANTE 180 DIAS}

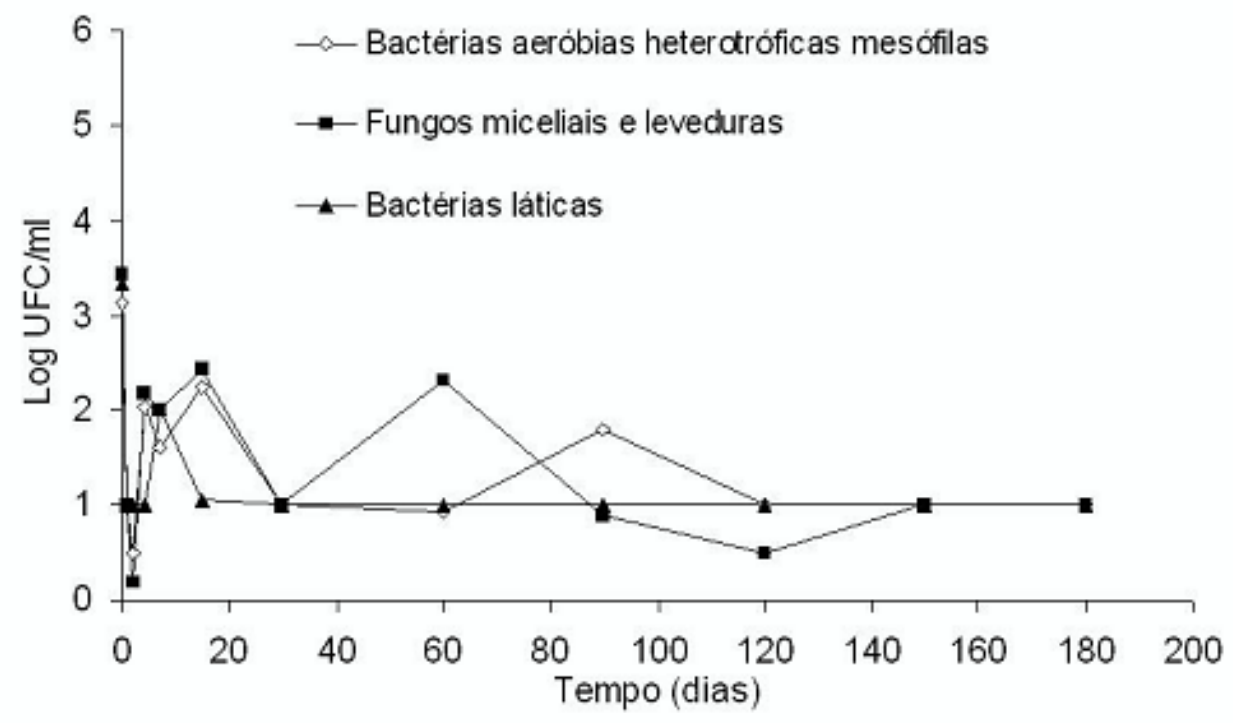


A redução inicial na contagem microbiana, observada tanto nos sucos refrigerados quanto nos congelados, pode estar associada ao estresse celular devido à exposição a baixas temperaturas. Já o aumento observado a partir de 48 horas de armazenamento pode ser atribuído à replicação de microrganismos selecionados e adaptados a baixas temperaturas (POLYDERA, STOFOROS e TAOUKIS, 2003). De acordo com RUSSEL (2002), baixas temperaturas de estocagem reduzem a taxa de crescimento até mesmo dos microrganismos adaptados ao frio. Por isso, esse tem sido considerado método eficiente para aumentar a vida-de-prateleira de alimentos frescos e processados.

O aumento da acidez indica o início de deterioração ou fermentação da amostra (ESTEVE et al. 2005). Esse processo foi observado na amostra de suco armazenada em temperatura ambiente.

\section{CONCLUSÃo}

O teor de ácido ascórbico permaneceu estável em suco de laranja mantido em temperatura ambiente por 24 horas, armazenado sob refrigeração durante sete dias ou sob congelamento por 180 dias.

Observou-se aumento entre um e três ciclos logarítmicos na contagem de bactérias mesófilas heterotróficas aeróbias totais e de fungos miceliais e leveduras no suco mantido em temperatura ambiente por 24 horas.

Os resultados das análises microbiológicas ratificam que as baixas temperaturas de armazenamento, associadas à acidez do suco de laranja, foram eficientes para a manutenção da estabilidade microbiológica nas condições estudadas.

Os resultados indicaram que o suco de laranja pode ser estocado sob refrigeração por quatro dias ou sob congelamento durante 120 dias, sem que haja comprometimento da qualidade nutricional e sanitária do produto.

\section{ABSTRACT \\ CHEMICAL, PHYSICO-CHEMICAL AND MICROBIOLOGICAL STABILITY OF ORANGE JUICE, cV. "PERA", IN DIFFERENT STORAGE CONDITIONS}

This study aimed to evaluate chemical, physicochemical and microbiological stabilities of orange juice,cv. "Pera", kept at room temperature, under refrigeration or freezing for different storage periods. Ascorbic acid and total soluble solids content, total titratable acidity and $\mathrm{pH}$ were determined. Mesophilic bacteria, yeasts and moulds, lactic bacteria, total and fecal coliforms and Salmonella were subject to microbiological count. Ascorbic acid content and total soluble solids remained stable in all storage conditions. The same was observed for total titratable acidity and $\mathrm{pH}$ in most samples, except for frozen orange juice, in which these parameters varied from the $120^{\text {th }}$ day to the end. Salmonella spp., total and fecal coliforms were not found in any samples. The initial count of mesophilic bacteria, yeasts and moulds, and lactic bacteria were around $3 \mathrm{Log} \mathrm{CFU} / \mathrm{mL}$. In the juice stored at room temperature during 24 hours, an increase of 1.5, 2.3 and $3.4 \mathrm{Log} \mathrm{CFU} / \mathrm{mL}$ in the count of mesophilic bacteria, yeasts and moulds and lactic bacteria, respectively, was observed. In the juices kept under refrigeration the microbiological count did not exceed the initial one until the fourth day. In juices kept under freezing, the microbiological count remained lower than the initial one for 180 days. According to these results, in natura orange juice preserved its quality when stored under refrigeration for $48 \mathrm{~h}$ or under freezing during 120 days.

KEY-WORDS: CHEMICAL STABILITY; MICROBIOLOGICAL STABILITY; ORANGE JUICE.

\section{REFERÊNCIAS}

1 ALMEIDA C.A.N.; CROTT G.C.; RICCO R.G.; DEL CIAMPO L.A.; DUTRA-DE-OLIVEIRA J.E.; CANTOLINI A. Control of iron-deficiency anaemia in Brazilian preschool children using iron-fortified orange juice. Nutrition Research, v.23, n.1, p.27-33, Jan. 2003. 
2 ALMEIDA, Regiane Borges de; GUIMARÃES, Renata Paiva; CASTRO, Rose Elma Silveira; PINHEIRO, Márcia Soares; ARAÚJO, Kátia Gomes L.; VERRUMA-BERNARDI, Marta Regina. Estudo microbiológico e físico-químico do suco de laranja fresco comercializado em Niterói-RJ. In: CONGRESSO BRASILEIRO DE CIÊNCIA E TECNOLOGIA DE ALIMENTOS, 18., Porto Alegre, 2002. Anais... Porto Alegre: Sociedade Brasileira de Ciência e Tecnologia de Alimentos, 2002. CD-ROM.

3 AOAC. Association of Official Analytical Chemists. Official method of analysis of AOAC international. $16^{\text {th }}$ ed. Arlington, 1995.

4 ARRIGONI, O.; TULLIO, M.C. Ascorbic acid: much more than just an antioxidant. Biochimica Biophysica Acta, v.1569, n.1-3, p.1-9, Jan. 2002.

5 AUSTRALIAN DEPARTMENT OF HEALTH AND AGEING. Salmonellosis outbreak, South Australia. Communicable Diseases Intelligence, v.23, n.3, p. 73. Mar.1999.

6 AYHAN, Z.; YEOM, H.W.; ZHANG, Q.H.; MIN, D.B. Flavor, color, and vitamin C retention of pulsed electric field processed orange juice in different packaging materials. Journal of Agricultural and Food Chemistry, v.49, n.2, p.669-674, Jan. 2001.

7 BINGHAM, S.; RIBOLI, E. Diet and cancer - the European prospective investigation into cancer and nutrition. Nature Reviews, v.4, n.3, p. 206-215, Mar. 2004.

8 BRACKETT, R.E.; SPLITTSTOESSER, D.F. Fruits and vegetables. In: VANDERZANT, C.; SPLITTSTOESSER D. F. Compendium of methods for the microbiological examination of foods. $3^{\text {rd }}$ ed. Washington, DC: American Public Health Association, 1992. p.919-927.

9 BRASIL. Ministério da Saúde. RDC n 12, de 02/01/2001. Regulamento técnico sobre os padrões microbiológicos para alimentos. Diário Oficial [da] República Federativa do Brasil, Brasília. Disponível em: <http://www.anvisa.org.br/>. Accesso em: 10 dez. 2004.

10 BULL, M.K.; ZERDIN, K.; HOWE, E.; GOICOECHEA, D.; PARAMANANDHAN, P.; STOCKMAN, R.; SELLAHEWA, J.; SZABO, E. A.; JOHNSON, R.L.; STEWART, C.M. The effect of high pressure processing on the microbial, physical and chemical properties of Valencia and Navel orange juice. Innovative Food Science and Emerging Technologies, v.5, n.2, p.135-149, Jun. 2004.

11 BURDURLU, H. S.; KOCA, N.; KARADENIZ, F. Degradation of vitamin C in citrus juice concentrates during storage. Journal of Food Engineering, v.74, n.2, p. 211-216, May 2006.

12 CAMPELO, E.C.S.; MARTINS, M.H.B.; CARVALHO, I.T.; PEDROSA, E.M.R. Teores de vitamina "C" em polpas de acerola (Malpighia glabra L.) congeladas. Boletim do CEPPA, v.16, n.1, p.107-113, jan./jun.1998.

13 CORREAA-NETO, R.S.; FARIA. J.A.F. Fatores que influem na qualidade do suco de laranja. Ciência e Tecnologia de Alimentos, v.19, n.1, p.153-160, jan./abr.1999.

14 CORTE-ELEUTÉRIO, R.M.; SALGADO, J. Estabilidade do ácido ascórbico em suco congelado de acerola (Malpighia glabra L. - sinônimo M. puniciflora L.) durante o armazenamento. Boletim do CEPPA, v.15, n.2, p.101-112. jul./dez. 1997

15 DEUTSCH, J.C. Dehydroascorbic acid. Journal of Chromatography A, v.881, n.1-2, p.299-307, Jun. 2000.

16 DOGAN, C.; ERKMEN, O. High pressure inactivation kinetics of Listeria monocytogenes inactivation in broth, milk, and peach and orange juices. Journal of Food Engineering, v.62, n.1, p.47-52, Mar. 2004.

17 ECONOMOS, Christina; CLAY, William D. Nutritional and health benefits of citrus fruits. In: THE INTERGOVERNMENTAL GROUP ON CITRUS FRUIT, 12., 1999, Valencia. Disponível em: <http:// www.fao.org/documents/show_cdr.asp?url_file=/docrep/x2650T/x2650t03.htm. Acesso em: 01 jun. 2006.

18 ESTEVE, M.J.; FRÍGOLA, A.; RODRIGO, C.; RODRIGO, D. Effect of storage period under variable conditions on the chemical and physical composition and colour of Spanish refrigerated orange juices. Food and Chemical Toxicology, v.43, n.9, p. 1413-1422, Sep. 2005.

19 FALVELA, C.V. Frutas cítricas: as frutas são alimentos que oferecem uma grande variedade de sabores e aromas agradáveis. Nutrição Brasil, v.3, n.2, p.106-114, mar./abr. 2004. 
20 FAO. Food and Agriculture Organization of the United Nations. Commodities and Trade Division.Citrus Commodity notes 2004-05. Rome, 2005. Disponível em: <http://www.fao.org/es/ESC/en/20953/20990/ highlight_28187en.html> Acesso em 01 jun. 2006.

21 IAL. Instituto Adolfo Lutz. Normas Analíticas do Instituto Adolfo Lutz. 3.ed. São Paulo, 1985.

22 JOHNSTON, C.S.; BOWLING, R.D. Stability of ascorbic acid in commercially available orange juices. Journal of the American Dietetic Association. v.102, n.4, p.525-529, Apr. 2002.

23 KABASAKALIS, V.; SIOPIDOU, D.; MOSHATOU, E. Ascorbic acid content of commercial fruit juices and its rate of loss upon storage. Food Chemistry, v.70, n.3, p.325-328, Aug. 2000.

24 KAUR, C.; KAPOOR, H.C. Antioxidants in fruits and vegetables - the millennium's health. International Journal of Food Science and Technology, v.36, n.7, p.703-725, Oct. 2001.

25 KOPELMAN, I.J.; RAUCHWERGER, M. Shelf-life and microbial growth kinetics of fresh citrus juices: Shamouti orange. Journal of Food Processing and Preservation, v.8, n.2, p.241-250, Apr. 1984.

26 LAPPONI, J.C. Estatística usando Excel. São Paulo: Lapponi Treinamento e Editora, 2000. 450 p.

27 LEE, H.S.; COATES, G.A. Vitamin C in frozen, fresh squeezed, unpasteurized, polyethylene-bottled orange juice: a storage study. Food Chemistry, v.65, n.2, p.165-168, May 1999.

28 LOPES, M.L.M.; ALMEIDA, A.S.; PEREIRA, C.Q.; VALENTE-MESQUITA, V.L.; MIGUEL, M.A.L.; COELHO, A.I.M. Efeito de tratamentos de sanitização de laranjas na estabilidade microbiológica do suco. Revista Higiene Alimentar, v.17, n.104, p. 102-103, jan/fev. 2003.

29 MACHADO, Mírian Ribeiro Galvão; RODRIGUES, Sabrina Ávila. Avaliação microbiológica de sucos de laranja in natura comercializados na cidade de Pelotas-RS. In: CONGRESSO BRASILEIRO DE CIÊNCIA E TECNOLOGIA DE ALIMENTOS, 18., Porto Alegre, 2002. Anais ... Porto Alegre: Sociedade Brasileira de Ciência e Tecnologia de Alimentos, 2002. CD-ROM.

30 NAIDU, K. A. Vitamin C in human health and disease is still a mystery? An overview. Nutrition Journal, v.2, p.1-10, Oct. 2003.

31 NEVES, E.M.; DAYOUB, M.; DRAGONE, D.S.; NEVES, M.F. Citricultura brasileira: efeitos econômicofinanceiros, 1996-2000. Revista Brasileira de Fruticultura, v.23, n.2, p.432-436, Aug. 2001.

32 OLIVEIRA, J.J.V.; TOLEDO, M.C.F.; SIGRIST, J.M.; YOTSUYANAGI, K.; ATHIÉ, I. Avaliação da qualidade de laranja pêra após armazenamento com etileno. Boletim do CEPPA, v.20, n.2, p.363-373, jul./dez. 2002.

33 ÖZKAN, M.; AYSEGÜL, K.; CEMEROGLU, B. Effects of hydrogen peroxide on the stability of ascorbic acid during storage in various fruit juices. Food Chemistry, v.88, n.4, p.591-597, Dec. 2004.

34 PARISH, M.E. Microbiological concerns in citrus juice processing. Food Technology, n.45, n.4, p.128134, Apr. 1991.

35 PAULO, M.G.; MARQUES, H.M.C.; MORAIS, J.A.G.; ALMEIDA, A.J. An isocratic LC method for the simultaneous determination of vitamins $A, C, E$ and $B$-carotene. Journal of Pharmaceutical and Biomedical Analysis, v.21, n.2, p.399-406, Nov.1999.

36 POLYDERA, A.C.; STOFOROS, N.G.; TAOUKIS, P.S. Comparative shelf life study and vitamin C loss kinetics in pasteurized and high pressure processed reconstituted orange juice. Journal of Food Engineering, v.60, n.1, p.21-29, Nov. 2003.

37 RUSSEL, N.J. Bacterial membranes: the effects of chill storage and food processing. An overview. International Journal of Food Microbiology, v.79, n.1-2, p.27-34, Nov. 2002.

38 SADLER, G.D.; PARISH, M.E.; WICKER, L. Microbial, enzymatic, and chemical changes during storage of fresh and processed orange juice. Journal of Food Science, v.57, n.5, p.1187-1191, Sep./Oct. 1992.

39 SELLI, S.; CABAROGLU, T.; CANBAS, A. Volative flavour components of orange juice obtained from the cv. Kozan of Turkey. Journal of Food Composition and Analysis, v.17, n.6, p.789-796, Dec. 2004. 
40 SILVA, F.O. Total ascorbic acid determination in fresh squeezed orange juice by gas chromatography. Food Control, v.16, n.1, p.55-58, Jan. 2005.

41 SILVA, P.T.; FIALHO, E.; LOPES, M.L.M.; VALENTE-MESQUITA, V.L. Industrialized orange juices and refreshment prepared from orange juice powder: chemical and physicochemical stability. Ciência e Tecnologia de Alimentos, v.25, n.3, p.597-602, jul./sept. 2005.

42 VENDRAMINI, A.L.; TRUGO, L.C. Chemical composition of acerola fruit (Malpighia punicifolia L.) at three stages of maturity. Food Chemistry, 71, n.2 p.195-198, Nov. 2000.

43 ZERDIN, K.; ROONEY, M.L.; VERMUË, J. The vitamin C content of orange juice packed in an oxygen scavenger material. Food Chemistry, v.82, n.3, p.387-395, Aug. 2003.

\section{AGRADECIMENTOS}

Os autores agradecem a FAPERJ e a FUJB pelo apoio financeiro e ao Dr. H. Masuda (Instituto de Bioquímica Médica / UFRJ) pela colaboração nas análises cromatográficas. 